\title{
Acil Servisten Genel Cerrahiye Konsulte Edilen Olguların Tanısal Analizi
}

\author{
Diagnostic Analysis of Patients Referred From Emergency Unit to General Surgery
}

\author{
Oktay AYDIN ${ }^{1}$ \\ ${ }^{1}$ Gaziantep Dr. Ersin Aslan Devlet Hastanesi Genel Cerrahi Kliniği, GAZİANTEP
}

\begin{abstract}
ÖZET
Acil servisin özellikle de aciliyeti olmayan hastalar tarafindan kullanılması dünya çapında artarak büyüyen bir sorun olmaya devam etmektedir.

Ekim 2013- Aralık 2013 tarihleri arasında hastanemiz acil servisine başvuran ve genel cerrahi bölümüne konsülte edilen 599 hasta retrospektif alarak incelendi.

450 hastaya cerrahi uygulanmış olup, en sık karın ağrısı sebebiyle operasyon gerçekleştirilmilştir. Diğer tanılar ise yanık, travma ve aletle yaralanma olarak bildirilmiştir.

Tüm bu bilgiler ışığında doğru düzenleme ve uygulamalarla Acil Servisten Genel Cerrahiye refere edilecek olguların seçilmesinde, takibi ve tedavisinde en efektif metodların bulunmasına çalışılması gerektiğini düşünmekteyiz.
\end{abstract}

Anahtar Kelimeler: Acil servis, genel cerrahi, cerrahi aciller

\section{GİRIŞ}

Acil servisin özellikle de aciliyeti olmayan hastalar tarafından kullanılması dünya çapında artarak büyüyen bir sorun olmaya devam etmektedir. $\mathrm{Bu}$ sorun gerçekten acil müdahaleye ihtiyaç duyan hastalar ile yeterince ve zamanında ilgilenilememesi ile sonuçlanması bakımından oldukça önemli bir sorundur. Bununla birlikte acil servis birimlerinde en ciddi yoğunluk yaşanan birimlerden biri de yine genel cerrahidir (1-3).

$\mathrm{Bu}$ çalışmada Suriye sınırı bölgesinde hizmet vermekte olan 3.basamak sağlık kuruluşumuzda, acil servisten genel cerrahiye refere edilen vakaların demografik ve tanısal özelliklerini yansıtmayı amaçladık.

\begin{abstract}
The unproper use of emergency units especially non-emergent patients is still a growing issue in global World.

599 patients who referred to General Surgery from emergency unit between October to December 2013 included the study

450 patients underwent surgery. The most frequent diagnosis was acute abdominal pain and the other frequent diagnosis are burns, trauma and injuries.

We think that efforts must be directed to ensure a healthy selection methods to decide which patients referred to surgery and effective follow-up and treatment processes.
\end{abstract}

Keywords: Emergency unit, general surgery, emergency surgery

\section{HASTALAR VE YÖNTEM}

Ekim 2013- Aralık 2013 tarihleri arasında hastanemiz acil servisine başvuran ve genel cerrahi bölümüne konsülte edilen hastalar retrospektif olarak incelendi. Hastaların demografik özellikleri, genel cerrahi konsültasyon sonrası yatış ve taburcu oranları, genel cerrahi bölümüne yatan hastaların operatif nonoperatif takip oranları, opere edilen hastalardan karın ağrısı ve akut batın, yanık, travma ve yaralanmaya bağlı opere edilme oranlar1, International Classification of Diseases-10 (ICD-10) tanı kodlama sistemine göre tanıları değerlendirildi. 


\section{SONUÇLAR}

Ekim 2013- Aralık 2013 tarihleri arasında acil servise başvuran 154550 hastanın 599 u genel cerrahi bölümüne konsülte edilmiştir $(\% 2,58)$.

Konsüte edilen 599 hastanın 222'si (\%37,1) kadın, 377 'si $(\% 62,9)$ erkek hastadır. En s1k konsülte edilen yaş grubu 159 hasta $(\% 26,5)$ ile 21-30 yaş grubu, en az konsülte edilen 2 hasta $(\% 0,3)$ ile 0-10 yaş grubu hastalardır, bu hastaların 70’i (\%44) karın ağrısı tanısı ile konsülte edilmiştir. Konsülte edilen hastaların 14'ü ayaktan tedavi ile taburcu edilmiş, $585^{\prime}$ 'i genel cerrahi servisine yatırılmıştır $(\% 97,6)$.

Yatış1 yapılan 585 hastanın 215'i $(\% 36,8)$ kadın, 370’i $(\% 63,2)$ erkektir, en yüksek yatış verilen yaş grubu 149 hasta $(\% 25,4)$ ile 21-30 yaş grubu, en az konsülte edilen 2 hasta $(\% 0,3)$ ile $0-10$ yaş grubu hastalardır. Yatış yapılan 585 hastanın 450'sine cerrahi operasyon uygulanmış, 145 hasta nonoperatif takip edilmiştir.

Cerrahi uygulanan 450 hastanın 165'i $(\% 36,6)$ kadın, 285'i $(\% 63,3)$ erkektir, en yüksek opere edilen 129 hasta $(\% 28,6)$ ile 21 - 30 yaş grubu, en az opere edilen 2 hasta $(\% 0,4)$ ile 0-10 yaş grubu hastalardır. Bu 129 hastanın 70’i $(\% 54,2)$ karın ağrısı tanısı ile opere edilmiştir.

Opere edilen tüm hastalardan 31'i $(\% 6,8)$ yanık, 69 $(\% 24,6)$ 'u travma ve yaralanma, 309'u $(\% 68,6)$ akut batın tanıları ile opere edilmiştir.

\section{TARTIŞMA}

Acil servislerin yoğunluğu gözönüne alındığında konsültan bölümlerin önemi de daha çok ortaya çıkmaktadır. Özellikle son yıllarda acil pratiği sırasında halktan da kendisini bir branş hekiminin değerlendirmesi yönünde baskılar artmaktadır. Bu durumda ilgili hekimler de konsültasyon konusunda değerlendirmelerini genellikle bu yönde yapmakta ve acil servisin yoğunluğu da katlanarak artmaktadır $(1,4)$.

$\mathrm{Bu}$ konuya Amerikan Ulusal Hasta Bilgi

Değerlendirme Komitesi (NCEPOD) de özellikle dikkat çekerek, cerrahi birimlere konsulte edilen olguların düşük operasyon oranlarını vurgulamıştır (4). $\mathrm{Bu}$ konuyla ilgili birçok çalışmada acil servisten cerrahi branşlara konsulte edilen olguların, cerrahi ekip üzerindeki iş yükü'ne etkisi ve bu yükün azaltılması için ne gibi önlemler alınabileceği tartışılmıştır (5-7). Acil servisten konsulte edilen hastaların yoğunluğuna ilaveten, olguların acil serviste 4 saatten fazla bekletilmemesi prensibine dayanarak yapılan uygulamalar da bu konuda çeşitli önlemleri zorunlu kılmıştır. Mohamed ve ark. 2005 yılında yaptıkları bir çalışmada yalnızca acil servis hastaları ile ilgilenen ayrı bir ekip kurulması durumunda, bu ekibe konsulte edilen olguların sadece yarısının acilden refere edildiği diğer büyük bölümünün ise diğer ayaktan polikliniklerden konsulte edildiğini saptadılar. $\mathrm{Bu}$ durumda yalnız cerrahi acillere bakan ekiplerin kurulması durumunda hem acil servis ve hem de Genel Cerrahi kliniklerinin daha efektif olarak kullanılabileceğini belirtmiştir (5).

Javaid ve arkadaşlarının yaptığı bir çalışmada ise Genel Cerrahi ekibin günde ortalama 5,5 saatini acil servis konsültasyonları için ayırdığı saptandı (6). Bu durumda Genel Cerrahi bölümünün acil servis ve travma yönetiminin ne kadar büyük bir kısmını oluşturduğu daha iyi anlaşılacaktır. Hatta aynı çalışmada özellikle multitravma sözkonusu olduğunda Genel Cerrahi'den 'ekibin kaptanı' olarak bahsedilmektedir. Literatürde Genel Cerrahiye konsulte edilen olguların yaklaşık olarak \%15-16'sının travma olduğu belirtilmekle birlikte (6), çalışmamızda bu oran oldukça yüksek bulunmuştur. Bunun majör sebebi elbette Suriye sınırında devam etmekte olan iç savaşın, sınır komşusu olarak bizim acil servis başvuru profilimize etki etmesidir.

Karın ağrısı ise literatürde de bizim çalışmamızda olduğu gibi en majör konsültasyon sebebi olarak karşımızda durmaktadır. Acil servislere çok sayıda hasta karın ağrısı ile başvurmakta ve ilk basamakta anamnez ve fizik muayene ile ayrilabilecek nedenler 
(a.gastroenterit gibi) ekarte edildikten sonra cerrahi açıdan değerlendirilmek üzere konsulte edilmektedir (6-8). Makalenin başında da vurguladığımız gibi iyi bir ilk değerlendirme ile Genel Cerrahi bölümünün efektif kullanımının amaçlanması önemlidir.

Yanıklar ise bir başka önemli konu olarak gündeme getirilmelidir. Yanık hususundaki en basit bilgiler bile erken ve etkin müdahalenin önemini işaret etmektedir (7). $\mathrm{Bu}$ sebeple yanık konsültasyonları bizim çalışmamızda en hızlı ve en efektif şekilde tedavi edilmek üzere acil bir şekilde servise yatırılan ve cerrahi müdahale yapilan hasta grubunu oluşturmaktadır.

Tüm bu bilgiler 1şı̆̆ında doğru düzenleme ve uygulamalarla Acil Servisten Genel Cerrahiye refere edilecek olguların seçilmesinde, takibi ve tedavisinde en efektif metodların bulunmasına çalışılması gerektiğini düşünmekteyiz.

\section{KAYNAKLAR}

1. Mai-Phan, TA., Patel B, Walsh M, Abraham AT, Kocher HM. Emergency room surgical workload in an inner city UK teaching hospital.World Journal of Emergency Surgery. 2008; (3):19.

2. Suen K, Hayes IP, Thomson BNJ, Shedda S. Effect of the introduction of an emergency general surgery service on outcomes from appendicectomy. BJS. 2014; 101: 141-6.
3. Faryniuk A, Hochman DJ. Effect of an acute care surgical service on the timeliness of care. Canadian Journal of Surgery. 2013; 56(3): 187.

4. Tincknell L, Burton S, Cooke C, Black S, Andreani S, Jourdan I, Gudgeon M. The emergency surgical team-the way forward in emergency care? Annals of the Royal College of Surgeons of England. 2009; 91(1): 12-18.

5. Mohamed MS, Mufti GR. The surgical assessment unit-effective strategy for improvement of the emergency surgical pathway? Journal of the Royal Society of Medicine. 2005; 98(1): 14-17.

6. Jawaid M, Raza SM, Alam SN, Manzar S. On-call emergency workload of a general surgical team. Journal of Emergencies, Trauma and Shock. 2009; 2(1):10-15.

7. Bell N. Does direct transport to provincial burn centres improve outcomes? A spatial epidemiology of severe burn injury in British Columbia, 20012006. Canadian journal of surgery. 2012; (55): 110.

8. Coşkun A. Acil cerrahi polikliniğine karın ağrısı ile başvuran hastaların çok yönlü prospektif değerlendirilmesi. Uzmanlık Tezi. İstanbul, 2009. 